\title{
The Cardioprotective Effects of Perindopril in a Model of Polymicrobial Sepsis: The Role of Radical Oxygen Species and the Inflammation Pathway
}

\author{
Atilla Topçu ${ }^{1}$, Ugur Kostakoglu ${ }^{1}$, Tolga Mercantepe ${ }^{1}$, Hulya Kilic Yilmaz ${ }^{1}$, Levent \\ Tumkaya ${ }^{1}$, and Huseyin $\mathrm{Uydu}^{1}$ \\ ${ }^{1}$ Recep Tayyip Erdoğan University Faculty of Medicine
}

May 5, 2020

\begin{abstract}
Mortality rates associated with myocardial dysfunction due to sepsis and septic shock are generally high across the world. Although symptomatic therapies are employed in an attempt to cope with the resulting complications, there is an urgent need for effective and reliable novel agents regulating oxidative stress and the inflammatory process in cardiac damage to be discovered and developed. The present study focused on the antioxidant and anti-inflammatory effects of perindopril for the purpose of preventing the adverse effects of sepsis on the myocardium and developing new alternatives in treatment. The control group received only saline solution via the oral route for four days. The second group underwent cecal ligation puncture (CLP), and the third underwent CLP and received PER $(2 \mathrm{mg} / \mathrm{kg})$. Rats in the third group received $2 \mathrm{mg} / \mathrm{kg}$ PER p.o. from four days before induction of sepsis. TBARS, total -SH, IL-1 $\beta$, IL-6 and 8-OHdG levels increased in the CLP groups. In contrast, PER $(2 \mathrm{mg} / \mathrm{kg})$ administered reduced the levels of biochemical parameters, apart from -SH, in rat heart tissues, and lowered 8-OHdG immunopositivity. The data from this study show that impairment of the antioxidant/antioxidant balance and inflammatory cytokine levels in favor of inflammation in heart tissue under septic conditions results in severe tissue damage. Per administration before sepsis was shown to exhibit antioxidant and anti-inflammatory properties by reducing these effects. This in turn increased the importance of PER as new evidence of its protective effects in heart tissue.
\end{abstract}

\section{Abbreviations}

ACE: angiotensin converting enzyme; ACEi: angiotensin converting enzyme inhibitor; Ang II: Angiotensin II; CLP: Cecal Ligation and Puncture; CRP: C-reactive protein; DNA: deoxyribonucleic acid; GSH: glutathione; HHS: Heart Histopathological Score; IHC: immunohistochemistry; IL-1 $\beta$ : interleukin-1 beta; IL6: interleukin-6; LPS: lipopolysaccharide; MDA: malondialdehyde; NF- $x$ B; nuclear factor kappa B; PER: Perindopril; RAAS: Renin angiotensin aldosterone system; ROS: Reactive Oxygen Species; TBARS: thiobarbituric acid reactive species; TNF- $\alpha$ : tumor necrotizing factor alpha; 8-OHdG: 8-hydroxy-2'-deoxyguanosine;

\section{INTRODUCTION}

Septic shock caused by sepsis is a health problem resulting in significant mortality(1). The inflammatory process caused by infection that leads to sepsis and progresses with dysfunction of more than one organ is the main sepsis-related cause of death(2). Patients with sepsis and septic shock resulting from sepsis represent a large part of intensive care patients worldwide. While healing may be observed in these patients after traditional treatment, the mortality rate with septic shock during this process stands at $25-30 \%$, and can even be as high as $40-50 \%(3)$. 
Dysfunction in the hemodynamic and cardiovascular system caused by the inflammatory mechanism results in decreased contraction by affecting the myocardium and subsequent cardiac dysfunction. The main cause underlying this is left ventricular dilatation and a depressed ejection fraction(4). Previous studies have reported a higher prevalence of mortality in septic patients with cardiovascular disease compared to patients with sepsis only $(5,6)$. Although the pathogenesis of the cardiac dysfunction caused by sepsis developing through complex pathways is still not fully understood, an increase in proinflammatory cytokine levels together with increasing oxidative stress in the inflammatory process result in a significant degree of myocardial function impairment(7).

Sepsis also causes an increase in thiobarbituric acid reactive species (TBARS), an important marker of tissue damage, by activating reactive oxygen species (ROS) through the oxidative stress pathway, thus contributing to the development of cardiac dysfunction(8). Previous studies have also shown that TBARS levels in heart tissue increase significantly in sepsis-induced inflammatory damage $(9,10)$. In addition to its antioxidant property, glutathione (GSH) also protects against developing oxidative stress, and is able to prevent more severe cardiac dysfunction by eliminating the effects of TBARS developing after damage(11).

Previous studies have shown that induction of damage with oxygen stress can result in an increase in proinflammatory cytokine levels $(12,13)$. In addition to an increase in the level of synthesis of the transcript factor nuclear factor kappa B (NF- $\varkappa \mathrm{B})$ in sepsis-related heart failure, it also leads to increases in levels of proinflammatory cytokines, such as tumor necrotizing factor alpha (TNF- $\alpha$ ), interleukin-1 beta (IL-1 $\beta$ ) and interleukin-6 (IL-6)(14) . If this synthesis pathway cannot be prevented, increasing inflammatory processes lead to increasing exacerbation of damage(15).

Oxidative stress induced following sepsis contributes to the development of DNA damage(16). Previous research has identified 8-hydroxy-2'-deoxyguanosine (8-OHdG) as one of the most important markers of this damage(17). However, there have been insufficient studies of 8-OHdG levels in heart tissue under septic conditions, and the present study was therefore intended to investigate the relationship between oxidative stress and DNA damage.

Perindopril is an ACEi that has long been used in the treatment of cardiovascular diseases(18). Research has also shown that perindopril possesses antioxidant, anti-inflammatory and antiapoptotic effects $(19,20)$. However, the mechanism by which ACEi ameliorate or eliminate damage occurring in the heart due to CLP-induced sepsis is still unclear.

The present prospective study was performed to examine the hypothesis that show that oxidative stress and inflammation resulting from cardiac damage in CLP-induced sepsis will decrease due to the potential antioxidant and anti-inflammatory effects of perindopril and that this may be a protective agent in preventing such damage, by means of biochemical, histopathological, and immunohistochemical methods.

\section{MATERIALS AND METHODS}

\section{Animals}

The research was conducted using cadaver tissues and sera obtained and left over from the study titled "The Protective Effects of Angiotensin-Converting Enzyme Inhibitor against Cecal Ligation and Puncture-Induced Sepsis via Oxidative Stress and Inflammation"approved by the ethical committee under decision No. 2019/30 dated 28.08.2019(21).

\section{Experimental Animals}

Twenty-four female Sprague Dawley rats weighing $290 \pm 10$ g were used for biochemical, histopathological and immunohistochemical analyses. The care provided for all animals was compatible with the principles set out in the National Research Council Guide for the Care and Use of Laboratory Animals and was also approved by the local ethical committee. Throughout the study, the rats were housed in standard plastic cages on sawdust flooring at $22 \pm 1^{\circ} \mathrm{C}$ and $55-65 \%$ humidity and under controlled lighting $(12 / 12 \mathrm{~h}$ dark/light cycle), with unrestricted access to standard rat chow and tap water. All animal experiments and procedures 
performed in the study were compatible with the national guidelines for the use and care of laboratory animals. Approval for the study protocol was granted by the Recep Tayyip Erdogan University local animal care comittee (approval number: 2019/01-31.01.2019).

Chemicals

Perindopril (Coversyl $10 \mathrm{mg} 30$ Film Tablets) was procured from Servier Ilaç ve Araştırma A.S. (Istanbul, Turkey) under licence from Les Laboratory Services, France. Ketamine hydrochloride (Ketalar@, 50 mg/kg, Pfizer Illaçları Ltd. Şti., Istanbul, Turkey) and sedative xylazine hydrochloride (Rompun®, $10 \mathrm{mg} / \mathrm{kg}$, Bayer, USA) were employed for anesthesia. Lidocaine hydrochloride (Jetokain@, $20 \mathrm{mg} / \mathrm{ml}$, Adeka, Samsun, Turkey) was performed analgesia. All chemicals employed in laboratory experiments were from Sigma Chemical Co. and Merck (Germany).

Experimental protocol

Rats were randomly and equally assigned into one of three groups. Group 1(n=8), the control group, received oral saline solution alone for four days. Group $2(\mathrm{n}=8)$, the CLP group, underwent cecal ligation and puncture induced sepsis with no drug administration. Group $3(\mathrm{n}=8)$, the CLP+PER $(2 \mathrm{mg} / \mathrm{kg})$ group, underwent CLP-induced sepsis and also received oral administration of $2 \mathrm{mg} / \mathrm{kg}$ PER for four days before induction of $\operatorname{sepsis}(21,22)$.

\section{Cecal Ligation and Puncture-Induced Sepsis Model}

Sepsis was induced in rats using the CLP-induced model described by Rittirsch D. et al.(23). All surgical procedures were carried out under sterile conditions. Rats were anesthetized with $50 \mathrm{mg} / \mathrm{kg}$ ketamine HCL injection and $10 \mathrm{mg} / \mathrm{Kg}$ xylazine HCL. Once the effect of the anesthesia had been confirmed, a $2.5 \mathrm{~cm}$ incision was made to the abdominal midline. The abdominal organs and cecum were isolated through this small incision, and the cecum was ligated distal to the ileocecal valve with a $3 / 0$ silk suture. The cecum content was attached to the peritoneum by opening two holes distal to the cecum from the mesentery to the opposite side with a 22-gauge needle. The abdominal incision was then closed with two layers of sterile synthetic absorbable $4 / 0$ suture. The wound was washed with $1 \%$ lidocaine for analgesia. The experiment was terminated 16 hours after the related treatments and surgery $(24)$.

At the end of the experiment, rats were sacrificed by euthanasia with the administration of high-dose anesthetic. Intracardiac blood specimens were collected immediately and centrifuged at $4000 \mathrm{rpm}$ for $10 \mathrm{~min}$ at $+4^{\circ} \mathrm{C}$. The heart was divided into longitudinal two, and a part of were stored with serum samples at $-80^{\circ} \mathrm{C}$ for use in biochemical studies. The other half was placed in $10 \%$ neutral formalin.

Biochemical procedure

Tissue Sampling and Homogenization

We first prepared $20 \mathrm{mM} 1 \mathrm{~L}$ sodium phosphate $+140 \mathrm{mM}$ potassium chloride (pH 7.4)(25). To $100 \mathrm{mg}$ hear tissue was added $1 \mathrm{ml}$ homogenate buffer and this was homogenized for $5 \mathrm{~min}$ at $30 \mathrm{~Hz}$ using a Tissue Lyser II device (Qiagen, Hilden, Germany) and then centrifuged for $10 \mathrm{~min}$ at $800 \mathrm{~g}$ at $4^{\circ} \mathrm{C}$. The resulting supernatant was used for TBARS, thiol, IL- $1 \beta$ and IL- 6 assays.

Standard solutions

Briefly, $82.5 \mu \mathrm{L} \mathrm{1,1,3,3-tetramethoxypropane} \mathrm{was} \mathrm{added} \mathrm{to} 0.01 \mathrm{M} 50 \mathrm{~mL} \mathrm{HCl} \mathrm{solution.} \mathrm{This} \mathrm{was} \mathrm{then} \mathrm{left}$ to incubate for $1 \mathrm{~h}$ at $50^{\circ} \mathrm{C}$. The concentration of this main stock solution was $10 \mu \mathrm{mol} / \mathrm{mL}$, from which 20 , $10,5,2.5,1.25$, and $0.625 \mathrm{nmol} / \mathrm{mL}$ standard solutions were prepared.

Thiobarbituric Acid Reactive Substances (TBARS) Concentration Assay

TBARS assay was performed using the method described by Ohkawa et al.(26). First, $200 \mu \mathrm{L}$ tissue supernatant was mixed with $50 \mu \mathrm{L}$ of $8.1 \%$ SDS (sodium dodecylsulphate), $375 \mu \mathrm{L} 20 \%$ acetic acid (v/v) pH 3.5, and $375 \mu \mathrm{L} 0.8 \%$ thiobarbituric acid (TBA). The resulting mixture was vortexed and left to incubate in a 
boiling water bath for $1 \mathrm{~h}$. Following incubation, the mixture was cooled for $5 \mathrm{~min}$ in ice water and then centrifuged at $750 \mathrm{~g}$ for $10 \mathrm{in}$. The resulting pink color was then read on a spectrophotometer at $532 \mathrm{~nm}$. The results were expressed as $\mathrm{nmol} / \mathrm{mg}$ prt.

Total Thiol (-SH) Assay

-SH group assays were performed using Ellman's reagent. Briefly, to $250 \mu \mathrm{L}$ supernatant was added 1000 $\mu \mathrm{L} 3 \mathrm{M} \mathrm{Na}_{2} \mathrm{HPO}_{4}$ and $250 \mu \mathrm{L}$ DTNB (4 mg $1 \%$ DTNB was prepared in $1 \% 10 \mathrm{~mL}$ sodium citrate solution) sit. This was then vortexed, and absorbance was determined at $412 \mathrm{~nm}$. The results were calculated with a $1000 \mu \mathrm{M}-62.5 \mu \mathrm{M}$ reduced glutathione standard chart and were expressed as $\mathrm{nmol} / \mathrm{mg}$ prt.

Interleukin 1 Beta (IL-1 $\beta$ ) and Interleukin 6 (IL-6) Measurements

Tissue IL- $1 \beta$ and IL-6 levels were determined with rat IL-1 $\beta$ and IL-6 ELISA kits (Catalog Nos. E-EL-R0012 and E-EL-R0015, respectively; Elabscience Inc. Wuhan, China) (Sensitivity: $18.75 \mathrm{pg} / \mathrm{mL}$, Detection Range: 31.25-2000 pg/mL and Repeatability: Coefficient of variation $<10 \%$; Sensitivity: $7.50 \mathrm{pg} / \mathrm{mL}$, Detection Range: $12.50-800 \mathrm{pg} / \mathrm{mL}$, respectively). Tissue homogenates were produced in a laboratory setting as specified by the manufacturer. Tissue IL- $1 \beta$ and IL- 6 concentrations in each specimen were measured in duplicate, as recommended by the manufacturer.

Histopathological Analysis

Heart tissue specimens were divided into $1.5 \mathrm{~cm}^{3}$ sections and fixed in $10 \%$ neutral formalin solution (Merck GmbH, Darmstadt, Germany) for $24 \mathrm{~h}$. Specimens of the fixed heart tissues were dehydrated by being passed through increasing ethanol (Merck GmbH, Darmstadt, Germany) series, and was then cleared in xylol (Merck GmbH, Darmstadt, Germany). In the next stage, heart tissue specimens were kept in soft paraffin (Merck GmbH, Darmstadt, Germany) for $1 \mathrm{~h}$, stored overnight in hard paraffin (Merck GmbH, Darmstadt, Germany) and embedded in paraffin blocks. Sections 4-5 $\mu \mathrm{m}$ in thickness were taken from the paraffin blocks using a rotary microtome (Leica, RM2525, Germany) and stained with Harris hematoxylin (Merck GmbH, Darmstadt Germany) and eosin G (Merck GmbH, Darmstadt, Germany).

Immunohistochemical (IHC) Analysis

8-Hydroxy-2'-deoxyguanosine (8-OHdG; sc-66036, Santa Cruz Biotechnology, USA) primary antibody and an appropriate secondary antibody (Goat Anti-Rabbit IgG H\&L (HRP), ab205718, Abcam, UK) were used to show DNA damage caused by free oxygen radicals. Sections $2-3 \mu \mathrm{m}$ in thickness from the heart tissue paraffin blocks were placed onto positively charged slides (Patolab, PRC). Following dehydration, $\mathrm{H}_{2} \mathrm{O}_{2}$ and endogenous peroxidase procedures were performed in line with the instructions of the manufacturer of the primary antibody kits. In the next stage, heart tissue sections were incubated for $1 \mathrm{~h}$ with 8-OHdG primary antibodies and then for $1 \mathrm{~h}$ with secondary antibodies. Counterstaining was then applied with DAB chromogen (Dako, Denmark) and Harris hematoxylin (Merck GmbH, Darmstadt, Germany).

Semi-Quantitative Analysis

Heart Histopathological Score (HHS) values were calculated, as shown in Table 2, for H\&E-stained sections in line with the findings of previous experimental sepsis models. Fifteen different areas in each preparate from heart tissue sections from each rat were measured by two histopathologists blinded to the study groups.

Heart tissue sections incubated with 8-OHdG primary antibody were graded by two histopathologists blinded to the study groups, as shown in Table 4 . Semiquantitative analysis was applied to 20 randomly selected different areas in heart tissue sections from each rat.

Statistical Analysis

Data obtained from the different analyses were subjected to statistical analysis on SPSS 18.0 software (IBM Corp., NY, Armonk, USA). Following normality tests, data obtained from semiquantitative analysis were calculated as mean and $25 \%$ and $75 \%$ interquartile ranges. Intergroup differences were then evaluated using the Kruskal Wallis test followed by Tamhane's T2 test. p values $<0.05$ were regarded as statistically 
significant. Parametric data obtained from biochemical analysis were calculated as mean \pm standard deviation, and differences between groups were subjected to one-way analysis of variance (ANOVA) followed by the Tukey test. $p$ values $<0.05$ were regarded as significant.

\section{RESULTS}

Biochemical Results

TBARS and Thiol Levels Analysis Results

TBARS and total thiol levels (expressed as nmol/g tissue and $\mu \mathrm{mol} / \mathrm{g}$ tissue, respectively) were determined $16 \mathrm{~h}$ after CLP in order to examine the effects of the procedure on free oxygen radicals in myocardial tissue and the potential protective effect of PER. TBARS levels of $24.89 \pm 1.74 \mathrm{nmol} / \mathrm{g}$ tissue in the control group increased to $35.92 \pm 6.64 \mathrm{nmol} / \mathrm{g}$ tissue in the CLP group $(\mathrm{p}<0.01$, Table 1$)$. Total SH levels of $1.47 \pm 0.18$ $\mu \mathrm{mol} / \mathrm{g}$ tissue in the control group increased to $2.27 \pm 0.40 \mu \mathrm{mol} / \mathrm{g}$ tissue in the CLP group $(\mathrm{p}<0.01$, Table 1). TBARS levels of $35.92 \pm 6.64 \mathrm{nmol} / \mathrm{g}$ tissue in the CLP group decreased to $29.61 \pm 3.78 \mathrm{nmol} / \mathrm{g}$ tissue after PER administration ( $\mathrm{p}<0.05$, Table 1). Total $\mathrm{SH}$ group levels of $2.27 \pm 0.40 \mathrm{nmol} / \mathrm{g}$ tissue in the CLP group fell to $1.56 \pm 0.14 \mathrm{nmol} / \mathrm{g}$ tissue following administration of PER $(\mathrm{p}<0.01$, Table 1$)$.

IL-1 $\beta$ and IL-6 Analysis Results

Other biochemical parameters measured in this study were IL-1 $\beta$ and IL-6 levels. IL-1 $\beta$ and IL-6 levels in the control group were $5.22 \pm 2.55 \mathrm{ng} / \mathrm{g}$ tissue and $2.25 \pm 1.18 \mathrm{ng} / \mathrm{g}$ tissue, respectively, compared to 6.22 $\pm 2.56 \mathrm{ng} / \mathrm{g}$ tissue and $2.41 \pm 1.07 \mathrm{ng} / \mathrm{g}$ tissue in the group with sepsis induced by CLP. Levels in the PER treatment groups decreased to $4.56 \pm 1.05 \mathrm{ng} / \mathrm{g}$ tissue and $1.60 \pm 0.35 \mathrm{ng} / \mathrm{g}$ tissue, respectively. Statistical analysis revealed no significant difference in IL-1 $\beta$ and IL-6 levels between the groups (p>0.05; Table 1).

Histopathological Results

Examination of control group tissues under light microscopy revealed cardiomyocytes with normally organized isotropic and anisotropic bands. In addition, connections were maintained between the discus intercalaris and cardiomyocytes (Figure 1a-b; median HHS score: 1.00 (0.5-1.5)). In contrast, degenerative cardiomyocytes with widespread loss of connections to the discus intercalaris were only observed in heart tissue sections from the CLP application. Widespread vascular congestion, together with edematous areas, albeit few in number, were also present (Figure 1c-d; mean HHS score: 5.00 (5-5.5)). A decrease in the number of degenerative cardiomyocytes was observed in the PER treatment group, and typical cardiomyocytes preserving their connections to the discus intercalaris were also determined. We also observed marked decreased in vascular congestion and edematous areas (Figure 1e-f; mean HHS score: 2.00 (1.5-2)).

Immunohistochemical Results

Cardiomyocytes in heart tissue sections incubated with 8-OHdG primary antibody from the control group exhibited a normal architecture (Figure 2a-b; Table 4; median 8-OHdG positivity score: 0.0(0-0.5)). However, cardiomyocytes exhibiting 8-OHdG positivity were observed in heart tissue sections from the CLP treatment group (Figure 2c-d; Table 4; median 8-OHdG positivity score: 2(2-2)). The number of cardiomyocytes exhibiting 8-OHdG positivity in heart tissue sections incubated with 8-OHdG primary antibody from the PER treatment group decreased, and widespread cardiomyocytes with a typical architecture were observed (Figure 2e-f; Table 4; median 8-OHdG positivity score: 1(0-1)).

\section{DISCUSSION}

The biochemical and histopathological examinations performed in this research show that myocardial damage resulting from ROS and inflammation caused by CLP-induced sepsis can be reduced by the ACEi PER. Myocardial dysfunction emerging together with damage in several vital organs is of vital importance in the pathogenesis of sepsis. In the present study, oxidative stress and inflammation resulting from sepsis triggered cardiac damage, while PER treatment applied in order to determine its protective effect contributed significantly to preventing that damage in association with its antioxidant and anti-inflammatory properties. 
A sepsis related model of myocardial damage has frequently been employed in previous experimental studies, and the purpose of the present study was to investigate the effects of PER treatment on heart tissue damage resulting from this method(27). In additional, the experimental animals in this study were supported by the 3R principle (Replacement, Reduction, Refinement) involving new humane animal welfare rules applied in several countries under the European framework.

Oxidative stress and inflammation emerging with polymicrobial sepsis primarily result in endothelial damage, although Angiotensin II (Ang II) can also cause cardiac function impairment by contributing to endothelial dysfunction through a similar mechanism(28). In contrast, PER is also known to exhibit cardioprotective effects(29). Moreover, in their experimental research Kostakoglu and Wiel et al. reported that PER prevents the progression of developing organ damage through its antioxidant and anti-inflammatory effects $(21,30)$. From that perspective, similar results were also obtained in the present study.

Impairment of the oxidant/antioxidant balance at the cellular level in tissue will cause organ damage if not corrected(31). One of the most important parameters in showing the level of damage occurring in issue under the effect of ROS is TBARS(32). TBARS makes it possible to determine concentrations of malondialdehyde (MDA), the final product forming after lipid peroxidation(33). Previous research has shown that TBARS levels increase significantly compared to control groups in sepsis-induced cardiac damage (34). Yang et al. reported significantly higher MDA levels in sepsis-induced myocardial damage compared to a control group(34). Similarly to these studies, we also determined an increase in MDA levels in heart tissue with sepsis-induced injury. Out study is therefore consistent with previous research from that perspective. In addition, MDA concentrations in the treatment groups also decreased compared to the case groups(35). Ji-Qiu Zhou et al. and Cheng Yang et al. previously observed that MDA levels decreased in their treatment groups. Similarly in the present study, MDA levels decreased in the group receiving PER, thus revealing that the drug possesses protective antioxidant properties(36).

The second most important parameter examined in this study was glutathione (GSH) levels. GSH is one of the most important known endogenous antioxidants(37). It exhibits a protective effect against increased lipid peroxidation following tissue damage. However, GSH levels decrease in case of increasing damage. Its effect is thus reduced, and oxidative stress-related damage occurs in tissue(38). A significant decrease in GSH levels has been reported following myocardial damage established with sepsis induced by lipopolysaccharides(39) . Similarly, Lvyi Chen et al. also revealed that GSH levels decrease due to sepsis(39). In the present study, however, GSH levels increased compared to the control group in the case group with induced sepsis. This was consistent with our previous study of the effect of PER on sepsis-induced lung injury(21). However, the inconsistency with previous studies suggests that agents with some antioxidant capacity are capable of increasing levels of GSH that can synthesized endogenously(37). This effect may be due to endogenous antioxidant systems and producing a protective effect in association with an increasing oxidant effect at the cellular level. This was also compatible with Ehab A M El-Shoura et al.'s study showing the antioxidant effects of $\operatorname{PER}(40)$.

Oxidative stress that increases following CLP-induced sepsis also causes a dramatic increase in myocardial damage by suppressing the inflammatory response(41). Previous studies have shown that proinflammatory cytokine levels increase throughout sepsis $(12,42)$. Huili Zhang et al. reported that NF- $\varkappa \mathrm{B}$, a transcript factor that increases with sepsis induction, increased synthesis of proinflammatory cytokines, particularly TNF- $\alpha$, IL-1 $\beta$, and IL-6(43). Additionally, Di Wu et al. showed that IL-1 $\beta$ synthesis decreased in proportion to NF- $x \mathrm{~B}$ expression under septic conditions(44). Similarly to previous research, the present study revealing the effect of sepsis in myocardial damage also showed that sepsis IL-1 $\beta$ levels increased in myocardial tissue with sepsis. In contrast, we determined that cytokine levels decreased in the group treated with PER. This was in agreement with our previous study(21). This was also consistent with Ehab A. M. El-Shoura et al.'s research revealing the protective effect of PER against cardiopulmonary damage(45). Another cytokine investigated in the present study IL-6, which produced similar effects to those of IL-1 $\beta$, further evidence that PER application produces an anti-inflammatory effect.

Another finding evaluated in this study was obtained using histopathological analysis to reveal damage in 
heart tissue occurring due to sepsis. Degeneration of cardiomyocytes due to sepsis resulted in heart damage in the present research, a finding consistent with Duzen I.V. et al.(46). This finding was also similar to Yu T et al.'s study(47). In contrast, we observed a decrease in the numbers of damaged cardiomyocytes in heart tissues treated with PER. This finding was consistent with Ehab A. M. El-Shoura et al. who reported that PER reversed the effects of lipopolysaccharide-based cardiopulmonary damage(40).

Increasing oxidative stress due to sepsis is known to cause cardiac damage(48). One of the most important markers of oxidative stress, in addition to MDA and GSH, is 8-OHdG(49). Previous studies have shown that 8-OHdG levels rise following increasing mitochondrial DNA oxidation under the effect of ROS(50). Our immunohistochemical analysis of $8-\mathrm{OHdG}$ expression revealed a significant increase in cardiac damage induced with CLP, and this was also consistent with the increase in tissue MDA levels. These findings are a clear indication that sepsis causes significant damage in heart tissue under oxidative stress. However, Yeki, Masaru et al. showed that 8-OHdG expression levels that increased with oxidative stress were reduced by PER treatment(51). Similarly in the present study, immunohistochemical analysis revealed a significant decrease in 8-OHdG expression in our treatment group, and this finding was compatible with Yeki, Masaru et al.'s study.

PER is also known to exhibit cardioprotective effects in addition to its antihypertensive properties. Oxidative stress increasing under the effect of Ang II, and inflammation, cause significant endothelial dysfunction in particular, as well as contributing to the emergence of severe heart problems in the long term(29). In addition to being an enzyme inhibitor that controls the renin-angiotensin-aldosterone system (RAAS), PER also exhibits cardioprotective effects through the antioxidant and anti-inflammatory effects mechanisms revealed in this study.

One of the principal treatments of sepsis involves the use of powerful and sensitive antibiotics against the agent concerned(52). However, it should not be forgotten that the selection of an intensive and potent antibiotic in the therapeutic process can also lead to severe drug-related side-effects(53). In addition, increasing case numbers also lead to significant financial costs(54). Although symptomatic treatments aimed at coping with complications emerging in association with septic shock have been tried in addition to antibiotic therapy, there is still an urgent need for effective and reliable novel agents capable of eliminating oxidative stress and inflammation in cardiac damage through different pathways to be discovered and developed. A cecal ligation and puncture (CLP) sepsis model developed in experimental studies is one of the most frequently employed methods within that context(55).

The RAAS is known to serve as a regulator in several organs, and particularly the cardiovascular system(56). The most important effects of angiotensin II, the principal component of the RAAS, are to induce myocardial hypertrophy, and thus to trigger inflammation in addition to increasing oxidative stress $(57,58)$. Previous research has revealed that angiotensin II contributes to the initiation and maintenance of a NF-K $\beta$-mediated proinflammatory process(59). Angiotensin converting enzyme inhibitors (ACEi), frequently employed in heart failure and other cardiac pathologies in particular, heralded a new age in treatment(60). Previous studies of ACEi have also shown that they possess antioxidant, anti-inflammatory, and antiapoptotic effects(61).

One limitation of the present study is that serum procalcitonin, C-reactive protein, and Ang II could not be measured. Nevertheless, this is an important pilot study showing the antioxidant, and anti-inflammatory effects of PER in heart tissue. It needs to be supported by further studies examining hemodynamic characteristics of the heart and cellular mechanism of the antioxidant and anti-inflammatory effect.

The data from this study show that impairment of the oxidant/antioxidant balance in heart tissue under septic conditions and inflammatory cytokine levels altering in favor of inflammation result in significant tissue damage. The administration of PER prior to sepsis was shown to exhibit antioxidant and anti-inflammatory properties by reversing these effects. This further increased the importance of PER as new evidence of its protective effects in heart tissue.

\section{Authors' Contributions}


AT and UK conceived and designed the research. AT, UK, and LT conducted the experiments. TM, HKY, HAU and contributed new reagents or analytical tools. AT, TM and HAU analyzed the data. AT wrote the manuscript. All authors read and approved the manuscript.

\section{Funding}

This research did not receive any specific grant from funding agencies in the public, commercial, or not-forprofit sectors.

\section{Declaration of Competing Interest}

No authors have any conflict of interest to declare.

\section{REFERENCES}

1. Fleischmann C, Scherag A, Adhikari NKJ, Hartog CS, Tsaganos T, Schlattmann P, et al. Assessment of global incidence and mortality of hospital-treated sepsis current estimates and limitations. Am J Respir Crit Care Med. 2016;193(3):259-72.

2. Gatica S, Eltit F, Santibanez JF, Varela D, Cabello-Verrugio C, Simon F. Expression Suppression and Activity Inhibition of TRPM7 Regulate Cytokine Production and Multiple Organ Dysfunction Syndrome During Endotoxemia: a New Target for Sepsis. Curr Mol Med. 2019;19(8):547-59.

3. Vincent JL, Marshall JC, Namendys-Silva SA, François B, Martin-Loeches I, Lipman J, et al. Assessment of the worldwide burden of critical illness: The Intensive Care Over Nations (ICON) audit. Lancet Respir Med. 2014;2(5):380-6.

4. Sato R, Nasu M. A review of sepsis-induced cardiomyopathy. J Intensive Care [Internet]. 2015;3(1):1-7. Available from: http://dx.doi.org/10.1186/s40560-015-0112-5

5. Blanco J, Muriel-Bombín A, Sagredo V, Taboada F, Gandía F, Tamayo L, et al. Incidence, organ dysfunction and mortality in severe sepsis: A Spanish multicentre study. Crit Care. 2008;12(6):1-14.

6. Zanotti-Cavazzonia SL, Hollenberg SM. Cardiac dysfunction in severe sepsis and septic shock. Curr Opin Crit Care. 2009;15(5):392-7.

7. Morgan RW, Fitzgerald JC, Weiss SL, Nadkarni VM, Sutton RM, Berg RA. Sepsis-associated in-hospital cardiac arrest: Epidemiology, pathophysiology, and potential therapies. J Crit Care [Internet]. 2017;40:12835. Available from: http://dx.doi.org/10.1016/j.jcrc.2017.03.023

8. Rozenberg S, Besse S, Brisson H, Jozefowicz E, Kandoussi A, Mebazaa A, et al. Endotoxin-induced myocardial dysfunction in senescent rats. Crit Care. 2006;10(4):1-9.

9. Ritter C, Andrades M, Frota MLC, Bonatto F, Pinho RA, Polydoro M, et al. Oxidative parameters and mortality in sepsis induced by cecal ligation and perforation. Intensive Care Med. 2003;29(10):1782-9.

10. Yang C, Wu K, Li SH, You Q. Protective effect of curcumin against cardiac dysfunction in sepsis rats. Pharm Biol. 2013;51(4):482-7.

11. Motawi TK, Darwish HA, Abd El Tawab AM. The relative efficacy of aminoguanidine and pentoxifylline in modulating endotoxin-induced cardiac stress. Cell Biochem Funct. 2011;29(8):694-702.

12. An R, Zhao L, Xi C, Li H, Shen G, Liu H, et al. Melatonin attenuates sepsis-induced cardiac dysfunction via a PI3K/Akt-dependent mechanism. Basic Res Cardiol. 2016;111(1):1-15.

13. Ahmad A, Druzhyna N, Szabo C. Delayed treatment with sodium hydrosulfide improves regional blood flow and alleviates Cecal Ligation and Puncture (CLP)-induced septic shock. Shock. 2016;46(2):183-93.

14. Peng T, Lu X, Lei M, Moe GW, Feng Q. Inhibition of p38 MAPK decreases myocardial TNF-alpha expression and improves myocardial function and survival in endotoxemia. Cardiovasc Res. 2003;59(4):893900. 
15. Chen L, Deng H, Cui H, Fang J, Zuo Z, Deng J, et al. Oncotarget 7204 www.impactjournals.com/oncotarget Inflammatory responses and inflammation-associated diseases in organs. Oncotarget [Internet]. 2018;9(6):7204-18. Available from: www.impactjournals.com/oncotarget/

16. Bahar I, Elay G, Başkol G, Sungur M, Donmez-Altuntas H. Increased DNA damage and increased apoptosis and necrosis in patients with severe sepsis and septic shock. J Crit Care. 2018;43:271-5.

17. Ba X, Boldogh lstvan. 8-Oxoguanine DNA glycosylase 1: Beyond repair of the oxidatively modified base lesions. Redox Biol [Internet]. 2018;14(November 2017):669-78. Available from: https://doi.org/10.1016/j.redox.2017.11.008

18. Todd PA, Fitton A. Perindopril: A Review of its Pharmacological Properties and Therapeutic Use in Cardiovascular Disorders. Drugs. 1991;42(1):90-114.

19. Varin R, Mulder P, Tamion F, Richard V, Henry JP, Lallemand F, et al. Improvement of endothelial function by chronic angiotensin-converting enzyme inhibition in heart failure: Role of nitric oxide, prostanoids, oxidant stress, and bradykinin. Circulation. 2000;102(3):351-6.

20. Kobara M, Tatsumi T, Kambayashi D, Mano A, Yamanaka S, Shiraishi J, et al. Effects of ACE inhibition on myocardial apoptosis in an ischemia-reperfusion rat heart model. J Cardiovasc Pharmacol. 2003;41(6):880-9.

21. Kostakoglu U, Topcu A, Atak M, Tumkaya L, Mercantepe T, Uydu HA. The protective effects of angiotensin-converting enzyme inhibitor against cecal ligation and puncture-induced sepsis via oxidative stress and inflammation. Life Sci [Internet]. 2020;241(September 2019):117051. Available from: https://doi.org/10.1016/j.lfs.2019.117051

22. Mashhoody T, Rastegar K, Zal F. Perindopril may improve the hippocampal reduced glutathione content in rats. Adv Pharm Bull. 2014;4(2):155-9.

23. Rittirsch D, Huber-lang MS, Flierl MA, Ward PA. Immunodesing of experimental sepsis by cecal ligation and puncture. Nat protoc. 2009;4(1):31-6.

24. Cinar I, Sirin B, Aydin P, Toktay E, Cadirci E, Halici I, et al. Ameliorative effect of gossypin against acute lung injury in experimental sepsis model of rats. Life Sci [Internet]. 2019;221(November 2018):327-34. Available from: https://doi.org/10.1016/j.lfs.2019.02.039

25. Rojas DB, Gemelli T, De Andrade RB, Campos AG, Dutra-Filho CS, Wannmacher CMD. Administration of histidine to female rats induces changes in oxidative status in cortex and hippocampus of the offspring. Neurochem Res. 2012;37(5):1031-6.

26. Ohkawa H, Ohishi N, Yagi K. Assay for lipid peroxides in animal tissues by thiobarbituric acid reaction. Anal Biochem. 1979;95(2):351-8.

27. Jia J, Gong X, Zhao Y, Yang Z, Ji K, Luan T, et al. Autophagy enhancing contributes to the organ protective effect of alpha-lipoic acid in septic rats. Front Immunol. 2019;10(JUL):1-13.

28. Pingili AK, Jennings BL, Mukherjee K, Akroush W, Gonzalez FJ, Malik KU. 6ß-Hydroxytestosterone, a metabolite of testosterone generated by CYP1B1, contributes to vascular changes in angiotensin II-induced hypertension in male mice. Biol Sex Differ. 2020;11(1):4.

29. Ancion A, Tridetti J, Nguyen Trung M-L, Oury C, Lancellotti P. A Review of the Role of Bradykinin and Nitric Oxide in the Cardioprotective Action of Angiotensin-Converting Enzyme Inhibitors: Focus on Perindopril. Cardiol Ther. 2019;8(2):179-91.

30. Wiel E, Pu Q, Leclerc J, Corseaux D, Bordet R, Lund N, et al. Effects of the angiotensin-converting enzyme inhibitor perindopril on endothelial injury and hemostatin in rabbit endotoxic shock. Intensive Care Med. 2004;30(8):1652-9. 
31. Andrades M, Ritter C, De Oliveira MR, Streck EL, Fonseca Moreira JC, Dal-Pizzol F. Antioxidant treatment reverses organ failure in rat model of sepsis: Role of antioxidant enzymes imbalance, neutrophil infiltration, and oxidative stress. J Surg Res. 2011;167(2).

32. Tsikas D. Assessment of lipid peroxidation by measuring malondialdehyde (MDA) and relatives in biological samples: Analytical and biological challenges. Anal Biochem [Internet]. 2017;524:13-30. Available from: http://dx.doi.org/10.1016/j.ab.2016.10.021

33. Draper HH, Squires EJ, Mahmoodi H, Wu J, Agarwal S, Hadley M. A comparative evaluation of thiobarbituric acid methods for the determination of malondialdehyde in biological materials. Free Radic Biol Med. 1993;15(4):353-63.

34. Yang C, Xia W, Liu X, Lin J, Wu A. Role of TXNIP/NLRP3 in sepsis-induced myocardial dysfunction. Int J Mol Med. 2019;44(2):417-26.

35. Khodir AE, Ghoneim HA, Rahim MA, Suddek GM. Montelukast attenuates lipopolysaccharide-induced cardiac injury in rats. Hum Exp Toxicol. 2016;35(4):388-97.

36. Zhou J qiu, Xu X, Zhen W wei, Luo Y long, Cai B, Zhang S. Protective effect of citrulline on the hearts of rats with sepsis induced by cecal ligation and puncture. Biomed Res Int. 2018;2018.

37. Poprac P, Jomova K, Simunkova M, Kollar V, Rhodes CJ, Valko M. Targeting Free Radicals in Oxidative Stress-Related Human Diseases. Trends Pharmacol Sci [Internet]. 2017;38(7):592-607. Available from: http://dx.doi.org/10.1016/j.tips.2017.04.005

38. Holvoet P, Kritchevsky SB, Tracy RP, Mertens A, Rubin SM, Butler J, et al. Risk of Myocardial Infarction in Well-Functioning Composition Cohort. Heal (San Fr. 2004;53(June 1998).

39. Chen L, Liu P, Feng X, Ma C. Salidroside suppressing LPS-induced myocardial injury by inhibiting ROS-mediated PI3K/Akt/mTOR pathway in vitro and in vivo. J Cell Mol Med. 2017;21(12):3178-89.

40. El-Shoura EAM, Messiha BAS, Sharkawi SMZ, Hemeida RAM. Perindopril ameliorates lipopolysaccharide-induced brain injury through modulation of angiotensin-II/angiotensin-1-7 and related signaling pathways. Eur J Pharmacol [Internet]. 2018;834(March):305-17. Available from: https://doi.org/10.1016/j.ejphar.2018.07.046

41. Shi X, Liu Y, Zhang D, Xiao D. Valproic acid attenuates sepsis-induced myocardial dysfunction in rats by accelerating autophagy through the PTEN/AKT/mTOR pathway. Life Sci [Internet]. 2019;232(June):116613. Available from: https://doi.org/10.1016/j.lfs.2019.116613

42. Liu J, Li J, Tian P, Guli B, Weng G, Li L, et al. H2S attenuates sepsis-induced cardiac dysfunction via a PI3K/Akt-dependent mechanism. Exp Ther Med. 2019;4064-72.

43. Zhang H, Zhi L, Moochhala S, Moore PK, Bhatia M. Hydrogen sulfide acts as an inflammatory mediator in cecal ligation and puncture-induced sepsis in mice by upregulating the production of cytokines and chemokines via NF-xB. Am J Physiol - Lung Cell Mol Physiol. 2007;292(4):960-71.

44. Wu D, Shi L, Li P, Ni X, Zhang J, Zhu Q, et al. Intermedin1-53 Protects Cardiac Fibroblasts by Inhibiting NLRP3 Inflammasome Activation During Sepsis. Inflammation. 2018;41(2):505-14.

45. El-Shoura EAM, Sharkawi SMZ, Messiha BAS, Bakr AG, Hemeida RAM. Perindopril mitigates LPSinduced cardiopulmonary oxidative and inflammatory damage via inhibition of renin angiotensin system, inflammation and oxidative stress. Immunopharmacol Immunotoxicol [Internet]. 2019;41(6):630-43. Available from: https://doi.org/10.1080/08923973.2019.1688346

46. Duzen, IV; Oguz, E;Yilmaz, R; Taskin, A; Vuruskan, E; Cekici, Y; Bilgel, ZG; Goksuluk, H; Candemir, B; Sucu M. Lycopene has a protective effect on septic shock-induced cardiac injury in rats. Bratisl Lek Listy. 2019;120(12):919-23. 
47. Yu T, Liu D, Gao M, Yang P, Zhang M, Song F, et al. Dexmedetomidine prevents septic myocardial dysfunction in rats via activation of $\alpha 7 \mathrm{nAChR}$ and PI3K/Akt- mediated autophagy. Biomed Pharmacother [Internet]. 2019;120(July):109231. Available from: https://doi.org/10.1016/j.biopha.2019.109231

48. Giustina A Della, Bonfante S, Zarbato GF, Danielski LG, Mathias K, de Oliveira AN, et al. Dimethyl Fumarate Modulates Oxidative Stress and Inflammation in Organs After Sepsis in Rats. Inflammation. 2018;41(1):315-27.

49. He J, Niu Y, Wang F, Wang C, Cui T, Bai K, et al. Dietary curcumin supplementation attenuates inflammation, hepatic injury and oxidative damage in a rat model of intra-uterine growth retardation. $\mathrm{Br} \mathrm{J}$ Nutr. 2018;120(5):537-48.

50. Yamada K, Ueda K, Shirakawa H, Giriwono PE, Honda S, Sakurai H, et al. The effect of liver hydrolysate on chronic ethanol-induced hepatic injury in normal rats. Biol Pharm Bull. 2020;

51. Ueki, M;Koda, M;Matona, T;Sugihara, T;Maeda, K;Murawaki Y. Preventative and therapeutic effects of perindopril on hepatic fbrosis induced by bile duct ligation in ratse. Mol Med Rep. 2009;2:857-64.

52. Rhodes A, Evans LE, Alhazzani W, Levy MM, Antonelli M, Ferrer R, et al. Surviving Sepsis Campaign: International Guidelines for Management of Sepsis and Septic Shock: 2016. Vol. 45, Critical Care Medicine. 2017. $486-552 \mathrm{p}$.

53. Wolf TA, Wimalawansa SJ, Razzaque MS. Procalcitonin as a biomarker for critically ill patients with sepsis: Effects of vitamin D supplementation. J Steroid Biochem Mol Biol. 2019;193(July).

54. French CJ. The epidemiology of sepsis-is Australasia different? Crit Care Resusc. 2006;8(3):219-22.

55. Polat B, Cadirci E, Halici Z, Bayir Y, Unal D, Bilgin BC, et al. The protective effect of amiodarone in lung tissue of cecal ligation and puncture-induced septic rats: A perspective from inflammatory cytokine release and oxidative stress. Naunyn Schmiedebergs Arch Pharmacol. 2013;386(7):635-43.

56. De Mello WC. Local Renin Angiotensin Aldosterone Systems and Cardiovascular Diseases. Med Clin North Am [Internet]. 2017;101(1):117-27. Available from: http://dx.doi.org/10.1016/j.mcna.2016.08.017

57. Leong DP, McMurray JJV, Joseph PG, Yusuf S. From ACE Inhibitors/ARBs to ARNIs in Coronary Artery Disease and Heart Failure (Part 2/5). J Am Coll Cardiol. 2019;74(5):683-98.

58. Muller DN, Dechend R, Mervaala EMA, Park JK, Schmidt F, Fiebeler A, et al. NF- $x$ B inhibition ameliorates angiotensin II-induced inflammatory damage in rats. Hypertension. 2000;35(1 II):193-201.

59. Wolf G, Wenzel U, Burns KD, Harris RC, Stahl RAK, Thaiss F. Angiotensin II activates nuclear transcription factor- $\varkappa$ B through AT1 and AT2 receptors. Kidney Int. 2002;61(6):1986-95.

60. Metra M, Teerlink JR. Heart failure. Lancet [Internet]. 2017;390(10106):1981-95. Available from: http://dx.doi.org/10.1016/S0140-6736(17)31071-1

61. Abd El-Aziz MA, Othman AI, Amer M, El-Missiry MA. Potential protective role of angiotensinconverting enzyme inhibitors captopril and enalapril against adriamycin-induced acute cardiac and hepatic toxicity in rats. J Appl Toxicol. 2001;21(6):469-73.

\section{TABLES}

Table 1: Biochemical Analysis Results

\begin{tabular}{ll}
\hline Group & Vascular C \\
\hline Control & $0(0-0.5)$ \\
CLP & $2(1.5-2)^{\mathbf{a}}$ \\
CLP+PER & $0(0-1)$ \\
${ }^{\mathbf{a}} p=0.003$ versus the control group, ${ }^{\mathbf{b}} p=0.000$ versus the control group, Kruskal Wallis/Tamhane T2 test ${ }^{\mathbf{a}} p=0.003$ ve \\
\hline
\end{tabular}


\#: differs statistically significantly from the CLP+PER group at $\mathrm{p}<0.05$

*: differs statistically significantly from the other group(s) at $\mathrm{p}<0.01$

\begin{tabular}{lllll}
\hline Findings & Score & Score & Score & \\
\hline & $\mathbf{0}$ & $\mathbf{1}$ & $\mathbf{2}$ & $\mathbf{3}$ \\
Vascular & $<5 \%$ & $6 \%-25 \%$ & $26 \%-50 \%$ & $i 51 \%$ \\
Congestion & & & & \\
Edema & $<5 \%$ & $6 \%-25 \%$ & $26 \%-50 \%$ & $i 51 \%$ \\
Degenerative & $<5 \%$ & $6 \%-25 \%$ & $26 \%-50 \%$ & $i 51 \%$ \\
Cardiomyocytes & & & & \\
\hline
\end{tabular}

Table 2. Heart Histopathological Scores (HHS)

Table 3. Heart histopathological scores (median: 25\%-75\% interquartile range).

Table 4. 8-hydroxy-2'-deoxyguanosine(8-OHdG) positivity scores (median: 25\%-75\% interquartile range)

\begin{tabular}{ll}
\hline Group & 8 -OHdG positivity Score \\
\hline Control & $0(0-0.5)$ \\
CLP & $2(2-2)^{\mathbf{a}}$ \\
CLP+PER & $1(0-1)$ \\
${ }^{\mathbf{a}} p=0.000$ versus the control group, Kruskal Wallis/Tamhane T2 test & ${ }^{p} p=0.000$ versus the control group, Kruskal W \\
\hline
\end{tabular}

\section{FIGURES}



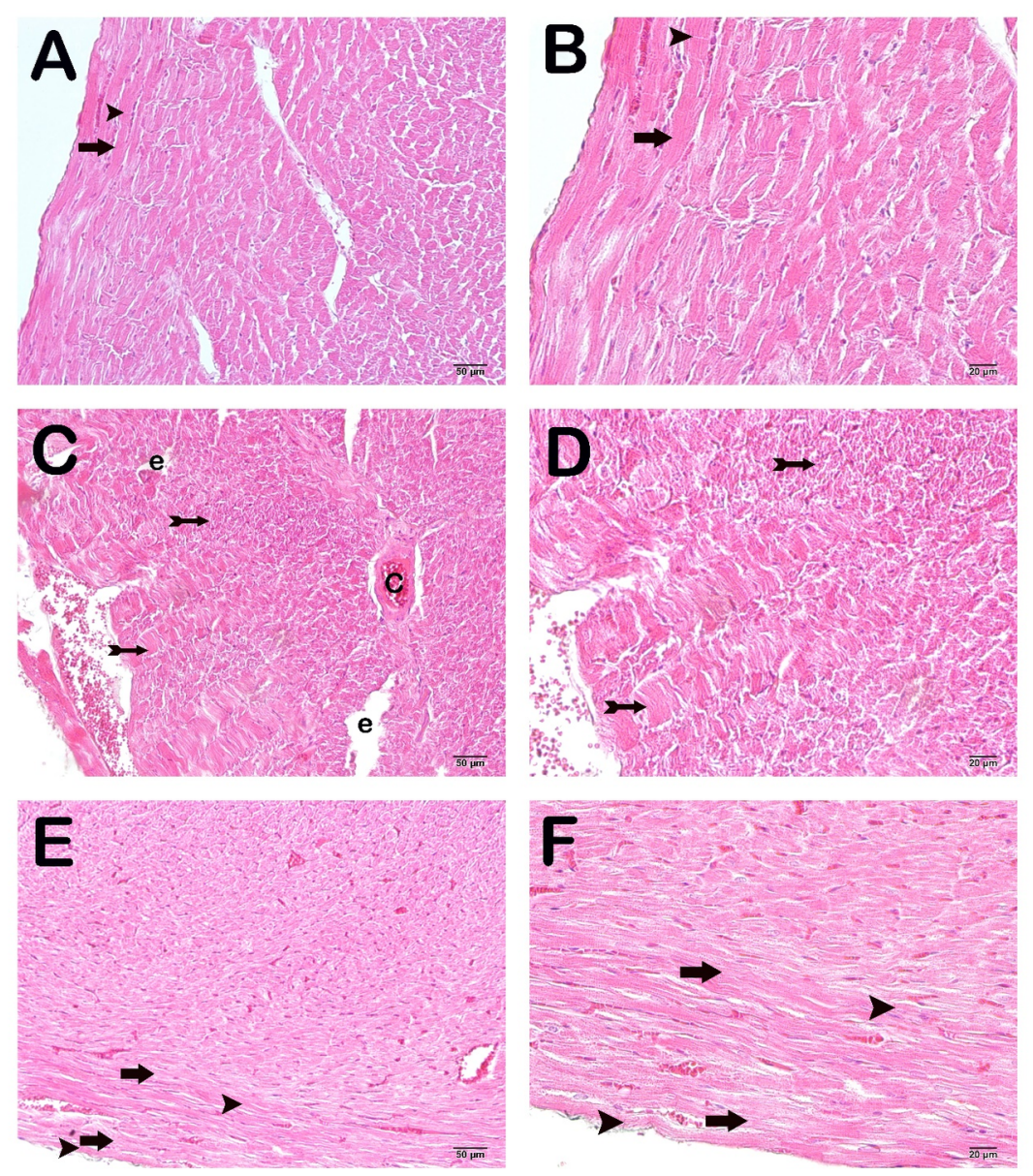

Figure 1. Representative light microscopic images of $H \& E$-stained heart tissue

A(x20)-B(x40): Control group sections showing cardiomyocytes with normal organization and isotropic and anisotropic bands (arrow) (median HHS:1.00(0.5-1.5)). Discus intercalaris (arrow head).C(x20)$\mathbf{D}(\mathbf{x} 40)$ : Sections from the CLP treatment group showing degenerative cardiomyocytes with isotropic and aniotropic bands (tailed arrow) and edematous areas (e) (median HHS: 5.00(5-5.5)). Vascular congestion can also be seen (c). $\mathbf{E}(\mathbf{x 2 0})-\mathbf{F}(\mathbf{x} 40)$ : Sections from the CLP+PER treatment group showing typical cardiomyocytes (arrow), together with a decrease in edematous areas and vascular congestion (media HHS: $2.00(1.5-2))$. 

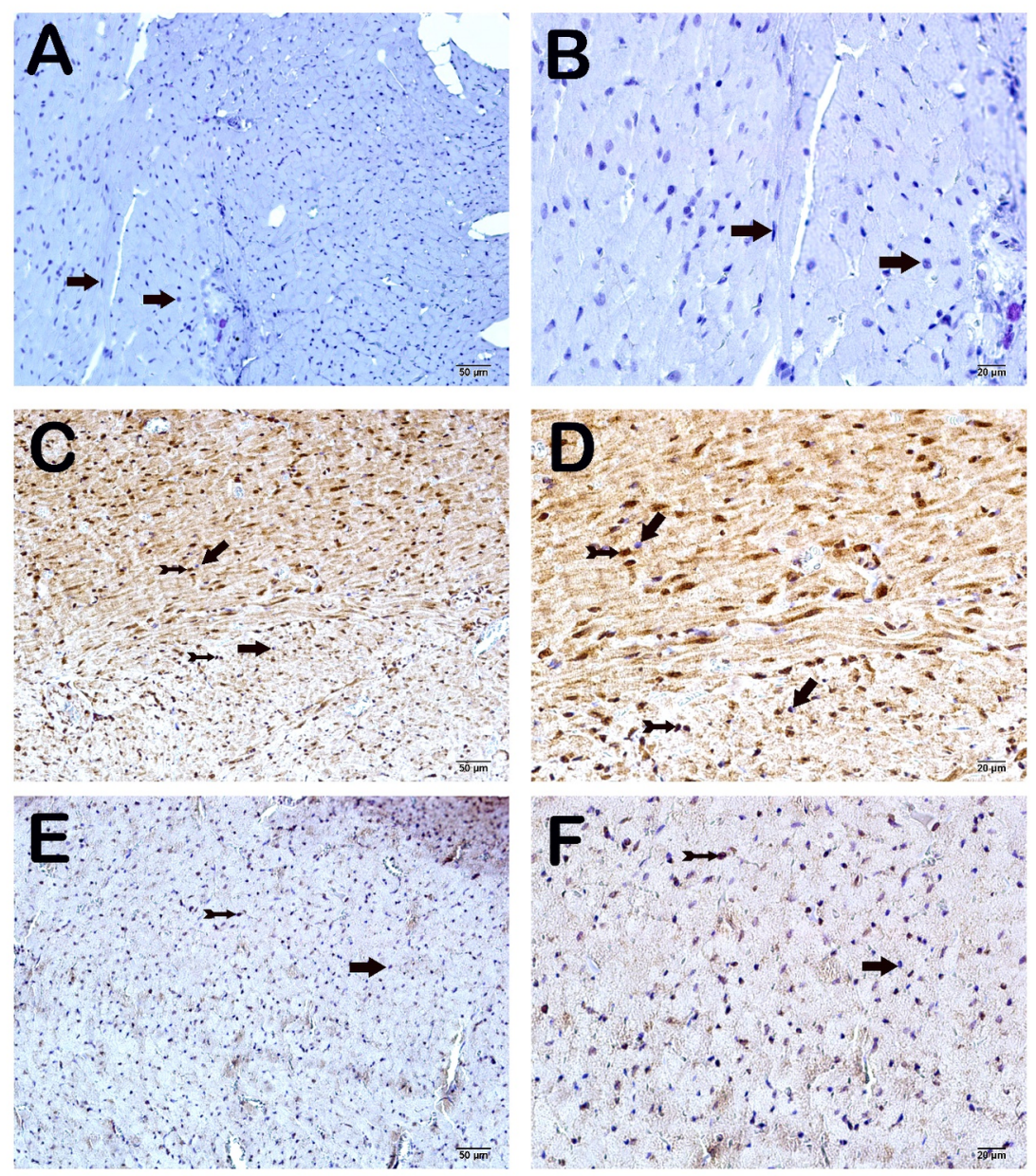

Figure 2. Representative light microscopic images of the change in the effect of oxidative DNA damage (8-hydroxy-2'-deoxyguanosine(8-OHdG)) caused by PER treatment after CLP-induced injury to cardiomyocytes.

A(x20)-B (x40): Control group heart sections showing normal cardiomyocytes (arrow) (median 8-OHdG positivity score: $0.0(0-0.5)) . \mathbf{C}(\mathbf{x} 20)-\mathbf{D}(\mathbf{x} 40)$ : CLP group sections showing cardiomyocytes with oxidative DNA damage (tailed arrow) (median 8-OHdG positivity score: 2.0(2-2)). E(x20)-F(x40): CLP+PER treatment group sections showing decreased apoptotic cardiomyocytes (tailed arrow). Numerous typical cardiomyocytes can also be seen (arrow) (median 8-OHdG positivity score: 1.0(0-1)).

\section{Hosted file}

Figure 1.jpg available at https://authorea.com/users/301745/articles/431597-thecardioprotective-effects-of-perindopril-in-a-model-of-polymicrobial-sepsis-the-roleof-radical-oxygen-species-and-the-inflammation-pathway

\section{Hosted file}

Figure 2.jpg available at https://authorea.com/users/301745/articles/431597-thecardioprotective-effects-of-perindopril-in-a-model-of-polymicrobial-sepsis-the-roleof-radical-oxygen-species-and-the-inflammation-pathway 